This item was submitted to Loughborough's Research Repository by the author.

Items in Figshare are protected by copyright, with all rights reserved, unless otherwise indicated.

\title{
Body image dissatisfaction and eating-related psychopathology in trans individuals: a matched control study
}

PLEASE CITE THE PUBLISHED VERSION

http://dx.doi.org/10.1002/erv.2362

\section{PUBLISHER}

(C) John Wiley \& Sons, Ltd and Eating Disorders Association

\section{VERSION}

AM (Accepted Manuscript)

\section{PUBLISHER STATEMENT}

This work is made available according to the conditions of the Creative Commons Attribution-NonCommercialNoDerivatives 4.0 International (CC BY-NC-ND 4.0) licence. Full details of this licence are available at: https://creativecommons.org/licenses/by-nc-nd/4.0/

\section{LICENCE}

CC BY-NC-ND 4.0

\section{REPOSITORY RECORD}

Witcomb, Gemma L., Walter P. Bouman, Nicola Brewin, Christina Richards, Fernando Fernandez-Aranda, and Jon Arcelus. 2019. "Body Image Dissatisfaction and Eating-related Psychopathology in Trans Individuals: A Matched Control Study”. figshare. https://hdl.handle.net/2134/18911. 
Running head: Trans individuals and eating disorder risk

Body image dissatisfaction and eating-related psychopathology in trans individuals: A matched control study.

Gemma L. Witcomb ${ }^{1}$, Walter Pierre Bouman ${ }^{2}$, Nicola Brewin ${ }^{3}$, Christina Richards ${ }^{2,5}$, Fernando Fernandez-Aranda ${ }^{4}$, \& Jon Arcelus ${ }^{1,2,3}$

${ }^{1}$ School of Sport, Exercise, \& Health Sciences, Loughborough University, Loughborough, LE11 3TU, UK.

${ }^{2}$ Nottingham Centre for Gender Dysphoria, Oxford Corner, 3 Oxford Street, Nottingham, NG1 5BH

${ }^{3}$ Leicestershire Adult Eating Disorder Service, Glenfield Hospital, Leicester, LE3 9DZ, UK.

${ }^{4}$ Department of Psychiatry, University Hospital of Bellvitge-IDIBELL and CIBERobn, Barcelona, Spain.

${ }^{5}$ Charing Cross Gender Identity Clinic, 179-183 Fulham Palace Road, London, W6 8QZ

Corresponding author: Dr Walter Bouman, Nottingham Centre for Gender Dysphoria, Oxford Corner, 3 Oxford Street, Nottingham NG1 5BH. Email: walterbouman@doctors.org.uk 
Running head: Trans individuals and eating disorder risk

\title{
Body image dissatisfaction and eating-related psychopathology in trans individuals: A matched control study.
}

\begin{abstract}
High levels of body dissatisfaction have already been reported in the trans population, however the root of this dissatisfaction, and its association with eating disordered behaviours, has not been studied in depth. This study aims to assess eating disorder risk by comparing 200 trans people, 200 people with eating disorders, and 200 control participants' scores on three subscales of the Eating Disorders Inventory-2; and to further explore dissatisfaction in the trans participants using the Hamburg Body Drawing Scale (HBDS). The results showed that overall participants with eating disorders scored higher than trans or control groups on all EDI-2 measures; but that trans individuals had greater body dissatisfaction than control participants and, importantly, trans males had comparable body dissatisfaction scores to eating disordered males. Drive for thinness was greater in females (cis and trans) compared to males. In relation to HBDS body dissatisfaction, both trans males and trans females reported greatest dissatisfaction not only for gender-identifying body parts but also for body shape and weight. Overall, trans males may be at particular risk for eating disordered psychopathology and other body image-related behaviours.
\end{abstract}

Keywords: transsexual, trans, drive for thinness, body dissatisfaction, eating disorder risk 
Running head: Trans individuals and eating disorder risk

Trans people are those people who are not content to remain the gender they were assigned at birth. Although a number of different terms have been used over the years to describe such individuals, the terms "trans individuals", "trans females" and "trans males" will be used throughout this paper to describe this population. In contrast the term cisgender is used to refer to those people who are content to remain the gender they were assigned at birth - i.e. they are non-trans people.

Trans females are those people assigned male at birth but who identify as female and trans males are those people who were assigned female at birth and who identify as male. Both groups will live in their preferred gender and many, but not all, will have interventions such as hormones and surgeries to effect a body in line with their identity. There are diagnoses associated with this condition, although the place of diagnosis is contested by clinicians working in the field (Richards \& Barker, 2013). Nonetheless it remains as Transsexualism, in the International classification of Disease $10^{\text {th }}$ edition (World Health Organisation, 1992), and is under review in preparation for the new edition of the ICD (ICD-11) where it is expected that it will include individuals who do not necessarily wish to transition from one binary point on a notional gender scale to the other (male to female or female to male). This will put it in line with the DSM-5 diagnosis of Gender Dysphoria (American Psychiatric Association (APA, 2013).

Estimates of the prevalence of trans people in the general population range from 0.45 (Wålinder, 1971) to 23.6 (Tsoi, 1988) per 100,000 people, with the variation explained by factors such as methodology used, country in which the study took place, year in which the study took place, and the means of classification used. 
Running head: Trans individuals and eating disorder risk

A recent meta-analysis of all appropriate studies found the prevalence for transsexualism to be 4.6 in 100,000 individuals; 6.8 for trans females and 2.6 for trans males, with time analysis finding an increase in reported prevalence over the last 50 years (Arcelus, Bouman, Van Den Noorgate, Claes, Witcomb \& FernandezAranda, under review). The prevalence of trans people within the clinical eating disorder population is unknown, although case studies do report trans people with eating disorder (e.g., Fernandez-Aranda et al., 2000; Hepp, Milos, \& Braun-Scharm, 2004; Hepp, Spindler \& Milos, 2005; Winston, Acharya, Chaudhuri, Fellowes, 2004).

Regardless of the desired gender, trans individuals may face a number of difficulties. For example, rates of mental health problems (McNeil, Bailey, Ellis, Morton \& Regan, 2012) and self-harm are high (Claes et al., 2014; Clark et al., 2014; Liu \& Mustanski, 2012), possibly due to limited social support (Davey, Bouman, Arcelus \& Meyer, 2014); as are experiences of harassment (Mitchell, Ybarra, \& Korchmaros, 2014; Whittle, Turner, \& Al-Alami, 2007). Notwithstanding this, one of the roots of distress felt by trans individuals is a high level of body dissatisfaction (Cuzzolaro, Vetrone, Marano, \& Garfinkel, 2006). This is not surprising, of course, as almost by definition, trans people feel dysphoria about their bodies, especially sexual characteristics such as breasts, penis, etc. This dysphoria has been shown to reduce with the use of hormone and surgical treatments (Bandini, 2013). For example, trans females taking oestrogens will experience finer and reduced facial and body hair growth; an increase in subcutaneous fat deposits and fat distribution around the hips and buttocks; breast growth; and reduced muscle bulk and definition - all of which help to promote a female appearance. Similarly, trans males taking testosterone will 
Running head: Trans individuals and eating disorder risk

no longer experience menses and will experience a redistribution of fat; increased muscle mass; and a deepening of the voice - which helps to promote more male appearance (Seal, 2007).

However, there are other aspects of appearance that are difficult or impossible to change with hormones or surgery often relating to skeletal changes at puberty such as body shape and weight; shoulder size, etc., which may be a continued source of body dissatisfaction. This can make the trans individual at risk of dietary restriction in order to modify their body shape towards their desired gender form (Algars, Alanko, Santtila, \& Sandnabba, 2012). Consequently it follows that trans individuals may represent a particularly vulnerable group for the development of disordered eating; both trans females who by birth sex tend to be larger and trans males who by birth sex have more fat stores. Furthermore, since internalisation of the "thin ideal" (the message communicated through media and culture that to be beautiful is to be thin) has been implicated as a risk factor for the development of eating disorders in females (Kroon Van Diest \& Perez, 2013; Witcomb, Arcelus, \& Chen, 2013), it is likely that trans females will internalise this message. If so, trans females may be particularly susceptible to developing disordered eating psychopathology, compared to trans males, due to their desire to not only achieve a congruent body but also one that conforms to the socially promoted thin ideal.

Until recently, little attention has been paid to the prevalence of disordered eating in the trans population. Studies investigating this association have either been case studies (Fernandez-Aranda et al., 2000; Hepp et al., 2004; Hepp et al., 2005; Winston et al., 2004); or have been methodologically limited by the small numbers of 
Running head: Trans individuals and eating disorder risk

individuals studied (e.g., Hepp \& Milos, 2002; Murray, Boon, \& Touyz, 2013) or the lack of matched controls.

An example of this is, Khoosal, Langham, Palmer, Terry, and Minajaji (2009) who compared scores on the Eating Disorders Inventory between 40 trans females (mean age $=41.8$ years), 147 female eating disorder patients $($ mean age $=27.0$ years) and standardised group norms from 577 control participants (mean age = 19.9 years) (Garner, Olmstead \& Polivy, 1983). They found that trans females scored similar to cisgender males, with lower drive for thinness, bulimia, and body dissatisfaction scores than those of cisgender females. However the authors of this study did not match both groups according to age, which limits the interpretation of the results, as eating disorder symptomatology has been associated to age (Hudson, Hiripi, Pope, \& Kessler, 2007). Furthermore, the study did not distinguish between trans individuals at different stages of transition (i.e. those who had not taken hormones and those who had), which is problematic in light of other studies that demonstrate how body image is altered by the use of cross sex hormones or surgery (e.g. Fisher et al., 2013).

Another limitation of previously conducted studies is the lack of strict criteria such as diagnosis being used to identify individuals. For example, Vocks, Stahn, Loenser, and Legenbauer (2009) concluded that although trans participants scored lower on various measures of eating psychopathology compared to those with diagnosed eating disorders, their (albeit non-significant) elevated scores in comparison to a control population suggest that they may still be at a higher risk of 
Running head: Trans individuals and eating disorder risk

eating disturbances. However, the trans participants were all self-identified (as opposed to having a formal diagnosis) which may have given rise to such a differing range of presentations as to obviate the findings. Similarly, another study that reports differences in eating psychopathology is based on comparisons between controls and those who report "gender identity conflict" (assessed by the Gender Identity Scale for Males [amended to include female-appropriate questions]; Freund et al.,1977), as opposed to patients with a strict diagnosis (Algars, Santtila \& Sandnabba, 2010).

Confirming diagnoses and matching participants on gender allows these potential confounds to be controlled. However, in studies involving trans participants, whether to match by birth assigned or identified gender is an complex question. Auer et al. (2013) investigated psychopathological symptom profiles in trans participants, matched with controls both on identified and birth assigned gender. Trans participants were found to display psychopathological profiles more similar to their counterparts who shared their identified gender - leading the authors to conclude that this may reflect a more appropriate comparison than matching according to birth assigned gender. Therefore, in the research study that forms the center of this paper, comparisons are made according to the trans participants' desired gender (i.e., cisgender female control participant and cisgender female eating disorder participant matched with a trans female participant).

After considering the existing literature, it was hypothesised that trans individuals will have both a higher drive for thinness and a higher body 
Running head: Trans individuals and eating disorder risk

dissatisfaction than healthy eating controls, but that this will be lower than seen in eating disorder controls. Furthermore, it was hypothesised that trans females will be more similar to cisgender female controls and that trans males will be more similar to cisgender male controls, than to their natal gender counterparts. Therefore, one of the aims of the current study was to explore eating psychopathology; body dissatisfaction; and gender differences across three groups of individuals matched on phenotypic gender - Those who fulfill diagnostic criteria for Transsexualism (ICD 10); those with a diagnosed eating disorder; and a cisgender control group who do not have an eating disorder.

Although body dissatisfaction has been reported to be a risk factor for eating disorders (Stice \& Shaw, 2002) elevated levels of body dissatisfaction that are driven by dissatisfaction with sexual characteristics may not pose such a risk. Understanding what is driving body dissatisfaction in trans individuals is important to understand when they might be at risk of developing eating disorders. In view of the above the second aim of the current study is to identify the nature of body dissatisfaction among trans individuals by investigating the specific body parts (e.g., genitals, voice, head, body shape) that cause discomfort to them.

\section{Method}

\section{Participants}


Running head: Trans individuals and eating disorder risk

Participants were recruited in three ways. Trans participants were recruited prospectively from all eligible referrals to an NHS Centre for Gender Dysphoria that spans all over the UK; eating disorder participants were recruited retrospectively from a clinical database at an NHS Adult Eating Disorder Service, covering a large county; and control participants were recruited prospectively, with additional data taken retrospectively, as part of an ongoing database of healthy controls at Loughborough University recruited from all over the UK. All participants were matched by gender; natal gender for the cis gender individuals matched with identified gender for the trans individuals (e.g., female control participant and female eating disorder participant, with a trans female (natal male) participant). Participants were not matched on any other socio-demographic variables as these were not available for all three groups.

Trans individuals. The sample consisted of all individuals who completed the assessment process at the Nottingham Centre for Gender Dysphoria (NCGD) in the United Kingdom during an 18 months period between January 2013 and June 2014. All consecutively referred individuals who following assessment fulfilled a diagnosis of Transsexualism by two independent gender specialists working at the Centre as per the ICD-10 (WHO, 1992); and were accepted for treatment were invited to participate in the study. During this period of time 345 referrals were made to the Centre. Out of the 345 referrals, 205 (59.4\%) completed the assessment and fulfilled the diagnostic criteria for Transsexualism according to the ICD-10 (WHO, 
Running head: Trans individuals and eating disorder risk

1992). One hundred and forty individuals were excluded, of whom 40 (28.6\%) did not attend, 49 (35\%) did not have their assessment completed during the study period, $15(10.7 \%)$ had socially transitioned and were on cross-sex hormone treatment before referral, and 36 (25.7\%) did not fulfill a diagnosis of Transsexualism. Of the remaining 205, 5 did not complete the questionnaires fully and so were excluded. This resulted in 200 trans participants (75 trans males and 125 trans females).

Eating disorder patients. The above participants were matched by identified gender with patients who had been assessed at the Leicestershire Adult Eating Disorder Service in the UK and diagnosed with an eating disorder. As the number of males assessed at the Service was smaller than the one assessed at the NCGD information from the most recent assessments between January 2007 and June 2014 was selected. Patients are assessed using the Clinical Eating Disorders Rating Instrument (CEDRI; Palmer et al., 1987) which is a semi-structured investigatorbased interview that measures eating-related behaviours and attitudes in accordance with DSM-IV criteria. The tool has been shown to have good reliability and validity (Palmer, Robertson, Cain \& Black, 1996).

Controls. Trans and eating disorder participants were also matched with two hundred control participants who were cisgender; not accessing any mental health services and not suffering from any eating disorder, measured by means of selfreport. They were selected (in chronological order based on desired gender i.e. first 75 males and the first 125 females) from a pool of 300 people recruited via an online survey hosted by Loughborough University between December 2012 and October 2013. A snowballing sampling technique was employed whereby links were posted 
Running head: Trans individuals and eating disorder risk

to social media networks or emailed to contacts and respondents were asked to share with their networks.

Ethical approval for the study was awarded by the NHS research ethics committee, after a full review. In addition, collection of data from each group was approved by the relevant research and development departments; the Nottinghamshire Healthcare NHS Trust for the trans participants and Leicestershire Partnership NHS Trust for the eating disorder participants. Recruitment of control participants was approved by the Loughborough University ethics committee.

\section{Measures}

Eating Disorders Inventory-2 (EDI-2, Garner, 1991). This was completed by all three groups and is a self-report questionnaire used to assess the presence psychological and behavioral traits of eating disorders. It consists of 11 subscales; three measure eating-related symptoms and the remainder measure psychological disturbances characteristic of those with clinical eating disorders - for example interpersonal distrust, fear of maturity, and perfectionism. The three subscales that measure eating-related behaviours were used in the present study. These were: 1) drive for thinness - seven questions that assess the extent to which an individual exhibits an excessive concern with dieting, preoccupation with weight, and fear of weight gain (for example, "I am terrified of gaining weight"); 2) bulimia - seven questions that assess whether and how often an individual reports episodes of binge eating and purging (for example, "I have gone on eating binges where I felt that I 
Running head: Trans individuals and eating disorder risk

could not stop"); and 3) body dissatisfaction - nine questions that assess the extent to which an individual is not satisfied with their physical appearance (for example, "I feel satisfied with the shape of my body"). Responses are made using a 6-point scale from "never", "rarely", "sometimes", "often", "usually", to "always". This questionnaire has been used widely in the literature and has been validated in the U.S. (Garner, 1991) and many European samples (e.g., Sweden; Nevonen \& Broberg, 2001, and Holland; van Strien \& Ouwens, 2003).

The Hamburg Body Drawing Scale (HBDS; Appelt \& Strauß, 1988). This was completed by the trans group only. It is a pictorial measure that asks participants to indicate how (dis)satisfied they are with specific parts of their body. Thirty-three different body characteristics (e.g., voice, skin, arms, chest, outer labia, penis) are identified on a body drawing and participants are asked to rate each (if applicable) on a 5-point Likert scale ranging from 1 ('very satisfied') to 5 ('very dissatisfied'). In addition, respondents are asked to give a rating for their overall whole body (dis)satisfaction and "other", if applicable. This scale has recently been validated for use in research with trans populations (Becker et al., 2014).

\section{Data Analysis}


Running head: Trans individuals and eating disorder risk

All data were analysed using SPSS 21. Multivariate $3 \times 2$ ANOVAs were performed to establish differences in the EDI-2 sub-scales between the three groups. As there is no non-parametric equivalent for a $3 \times 2$ comparison; and given that only some of the data were marginally non-normally distributed; and the robustness of ANOVA to deal with violations to normality assumptions, this was considered acceptable. For these ANOVAs, Group (trans / eating disorder / controls) and Gender / Identified Gender (male / female) were entered as factors. Any significant differences or interactions between groups were explored using Tukey's post hoc

test statistic. One-way ANOVAs were then used to compare the reported dissatisfaction with individual body parts between trans males and trans females. The level of significance used was $p<0.01$.

\section{Results}

Aim 1 involved 600 participants (mean age $=35.14$ years, $S D=57.04$ ); 200 individuals with a diagnosis of Transsexualism according to the ICD-10 (WHO, 1992); 200 individuals diagnosed with an eating disorder according to DSM-IV (APA, 1994) [54 anorexia nervosa (AN), 77 Bulimia Nervosa (BN), 69 Eating Disorders Not Otherwise Specified (EDNOS)]; and 200 controls. Each group was made up of 75 males (cisgender and trans males) and 125 females (cisgender and trans females). The groups did not differ in age $(F[1.67,2], p=0.19)$. Aim 2 involved the trans participants only; 75 trans males and 125 trans females.

Across the three groups, there was no effect of gender on age $(F[3.00,2]$, $p=0.084)$. However, taking each group individually, trans males were found to be 
Running head: Trans individuals and eating disorder risk

significantly younger (mean age $=25.36, S D=9.60)$ than trans females (mean age $=$ 38.56, $S D=14.21 ; F[50.74,1], p<0.0001)$. This reflects the numbers seen in clinical practice within NCGD referrals data.

\section{Aim 1: Eating psychopathology comparison across 3 groups}

Drive for thinness. There was a main effect of group $(F[233.16,2], p<0.0001)$ with post-hoc tests revealing that the eating disorder group had significantly higher scores than both the control (mean difference $=10.45$ ) and trans groups (mean difference $=9.44$; both $p<0.0001)$. The difference between trans and controls was not significant (mean difference $=1.11, p=0.76$ ). There was a main effect of gender $(F[20.51,1), p<0.0001)$, with cisgender females/trans females scoring higher than cisgender males/trans males. See Table 1 and Figure 1a. There was also a significant interaction between Group and Gender ( $F[5.64,2], p=0.004)$.

Bulimia. There was a main effect of group $(F[119.83,2], p<0.0001)$ with posthoc tests revealing that the eating disorder group had significantly higher scores than both the control (mean difference $=5.97$ ) and trans groups (mean difference $=5.73$; both $p<0.0001)$. See Table 1. There was no effect of gender or group and gender interaction. See Figure 1b.

Body dissatisfaction. There was a main effect of group ( $F[94.52,2]$, $p<0.0001$ ), with post-hoc tests revealing that the eating disorder group had significantly higher scores than both the control (mean difference $=10.13$ ) and trans groups (mean difference $=5.58$; both $p<0.0001$ ). The trans group also scored significantly higher than the control group (mean difference $=4.55, p<0.0001$ ). There 
Running head: Trans individuals and eating disorder risk

was a significant main effect of gender $(F[8.15,1], p=0.004)$, with the combined female groups scoring higher than combined male groups. See Figure 1c. However, there was also a significant interaction between group and gender $(F[29.97,2]$, $p<0.0001$ ) showing that the cisgender females and trans males were more dissatisfied than cisgender males and trans females (birth assigned male but identify as female). Trans males also had near identical body dissatisfaction scores to eating disorder males. See Figure 1c.

***Insert Table 1 and Figures 1a, 1b and 1c here ${ }^{\star \star *}$

\section{Aim 2: Body dissatisfaction comparison between trans males and trans females}

In order to further explore whether the root of body dissatisfaction differs between trans participants, all were asked to complete the Hamburg Body Drawing Scale (Appelt \& Strauß, 1988). The analysis revealed no significant differences between trans males and trans females in their dissatisfaction with specific body parts and overall dissatisfaction was similarly high in both groups (mean $=4.06$ in trans females $(S D=0.88)$ and trans males $(S D=0.91)$. The parts of the body that caused most dissatisfaction (mean of 3.5 or above) were: beard, body hair, skin, adam's apple, chest/breast, stomach, waist, hips, and bottom.

\section{Discussion}


Running head: Trans individuals and eating disorder risk

Previous studies have investigated body dissatisfaction in trans individuals. Although those studies were limited by the lack of matched controls (Khoosal et al., 2009), diagnostic tools (e.g., Vocks et al., 2009) and the small number of individuals involved in the project (e.g., Murray et al., 2013), they confirmed that trans individuals experience high levels of body dissatisfaction, that can be alleviated somewhat by beginning the process of physical transitioning to the gender which matches their internal identity. On the surface, this is perhaps not surprising, since transsexualism is defined by a feeling that one's body is not in line with one's experienced gender, and as a consequence is a cause of distress and dissatisfaction (ICD 10; World Health Organization, 1992). Previous studies have concluded that trans individuals may be at an increased risk of developing eating disorders compared to the general population because of their higher levels of body dissatisfaction (Cuzzolaro et al., 2006; Vocks et al., 2009). However, the source of the dissatisfaction is likely to be important in predicting whether this dissatisfaction is manifest in eating disordered behaviours. For example, dissatisfaction with hair is unlikely to be a risk factor for dietary restriction, whereas dissatisfaction with thighs may be.

The findings support previous research which has reported that trans individuals do not score as highly as those with clinical eating disorders, but that they may exhibit some greater eating disorder-related symptomology compared to controls (Vocks et al., 2009). On the measure of body dissatisfaction, not only did the eating disorder group score higher than the trans and control groups, but the trans groups also scored higher than the control group. Furthermore, trans males had 
Running head: Trans individuals and eating disorder risk

similarly high scores on body dissatisfaction as eating disordered males. The significant interaction indicated that body dissatisfaction is associated with being assigned female at birth (cisgender females and trans males). Therefore, while dissatisfaction tends to be higher in cisgender females than cisgender males, it is higher in trans males than it is in trans females (and as stated previously, at a level comparable with males with eating disorders). This confounds findings from the eating disorder field, where females show higher levels of body dissatisfaction than males (Nuñez-Navarro et al., 2012) and may point to protective effects of socialisation in a male role (trans females), or possibly some protective biological factor associated with being assigned male at birth.

Regarding drive for thinness and bulimia, trans and control individuals did not differ. However, higher scores in drive for thinness were associated with being female in the control and eating disorder group (with females scoring higher than males), but in the trans group there was little difference between desired genders; both trans males and trans females showed very similar levels of drive for thinness, which were comparable with cisgender females and higher than what is seen in cisgender males. This suggests that a female identity, by birth or by desire, may be a risk factor. Trans females may internalise the same ideals that natal females do with regard to the ideal female body (Hoek, 1993; Witcomb et al., 2013) while trans males may still be influenced by such cultural aspects of being female, despite desiring to be male.

When using the Hamburg Body Drawing Scale to assess dissatisfaction with specific body parts, no significant differences were found between trans males and 
Running head: Trans individuals and eating disorder risk

trans females. The body parts that were reported to cause the most dissatisfaction were those associated with body shape and those that could be considered to be associated with as attaining the outward appearance of the gender the person experiences themselves as. Dissatisfaction with body shape (stomach, waist, hips, and bottom) may, on the surface, suggest a risk for the development of eating disorders since the dissatisfaction is rooted in aspects of the body that could be changed by dietary restriction. Consequently both groups had near identical levels of drive for thinness. However, how this is manifest in eating behaviour may differ between trans males and trans females. In light of the association between being male and having greater muscle mass, it may be that some trans males will be at risk for other types of body image-related behaviours, such as body building and excessive exercise and the development of symptoms of muscular dysmorphia or dysmorphic disorders (Nieuwoudt, Zhou, Coutts, \& Booker, 2012). This is well documented in the cisgender population with sociocultural messages promoting becoming muscular predicting compulsive exercise in boys (Goodwin, Haycraft \& Meyer, 2014); and indeed body building, at extreme levels, has been termed 'bigorexia' (Mosley, 2009). Relatedly, for trans females, the influence of desired gender on drive for thinness may reflect what is seen in the general population, with some trans females internalising the same ideals that some cisgender females do with regard to the ideal female body, possibly because their female identity has been present for many years (reflected in the older age of the trans females attending clinic) (Hoek, 1993; Witcomb et al., 2013). There may also be a drive for thinness in a way that is quite specific to some trans people, by virtue of wanting to suppress 
Running head: Trans individuals and eating disorder risk

features of the birth assigned gender and to accentuate the features of the identified gender, as suggested by Algars et al (2012).

The influence of birth assigned gender on body dissatisfaction is more complex, with all birth assigned females (cisgender females and trans males) exhibiting greater levels of dissatisfaction than birth assigned males (cisgender males and trans females). When looking at dissatisfaction with specific parts of the body, there were no differences between trans males and trans females, but the parts of the body that caused the most dissatisfaction in both groups were those physical attributes that may most likely identify them as being trans, i.e. beard, body hair, skin, adam's apple, chest/breast.

There are aspects of the study that warrant attention in relation to limitation of the results. Firstly, this study compared trans patients and eating disorder patients from NHS Clinics. Therefore the data represent clinical cases only and can not be generalised to those individuals who are unwilling or unable to seek help and who are not within the NHS healthcare system. Furthermore, since this study investigated body dissatisfaction in trans individuals at the start of their transition, the pattern of results found here should not be generalised to all trans people, particularly those who have begun to undergo some physical transitions with the use of hormones. In addition, the cross-sectional nature of this research means that changes in body dissatisfaction over time and throughout the transitioning / treatment process can not be assessed. Therefore, further research should aim to investigate the risk of developing an eating disorder in the trans population in a longitudinal study. 
Running head: Trans individuals and eating disorder risk

Secondly, there are additional questions that require investigation. For example, stress is considered to be a precipitating factor in eating problems such as binge eating (Degortes et al., 2014) and, as such, future work would benefit from an inclusion of an assessment of stress (related to being trans and to the transitional process) in order to investigate whether trans individuals are more or less at risk for binge eating due to increased levels of minority stress related to being a marginalised group (Hendricks \& Testa, 2012). Future work should also consider what role individual factors which have been shown to be associated with the development of eating disorders in cisgender populations such as perfectionism (Boone, Soenens, \& Luyten, 2014) or anxiety (Waller, Ormonde, \& Kuteyi, 2013) also play a role in trans populations.

Finally, it is worth noting that all data were collected via self-report questionnaires (except diagnosis) and, as such, may be influenced by response bias. In addition, BMI was not recorded for all participants, which may have been interesting. Our main aim was to measure the levels of body dissatisfaction of trans people that traditionally attend Services. As such, we were keen not to introduce any measures that may reduce participation, since a large clinical sample of trans individuals is a real strength of the study. Although differences in BMI would clearly be present between eating disorder participants and the other two groups, there was no clinical reason to suggest that there would be BMI differences between trans and cis gender participants. However we acknowledge that future studies would benefit from including a measure of BMI if possible. 
Running head: Trans individuals and eating disorder risk

Since research in this area is relatively new, the tools used to measure body dissatisfaction and eating disorder symptomology are not widely validated and nor have they been designed specifically for use in this population - leaving their reliability and, crucially, validity open to question. As such, future research with trans populations would benefit from the development of reliable, validated measures to assess eating behavior and body image.

Overall, this study has shown that taking account of gender identity is crucial in understanding how body dissatisfaction might manifest itself in different populations. Although the etiology of eating disorders is multi-factorial and no one single element alone will precipitate an eating disorder, the results of this large, controlled study suggest that being birth assigned female (cis gender females and trans males) and desiring to be female (trans females) all carry a similar weight in terms of drive for thinness, which is greater than seen in non-trans, cisgender males. Most importantly, trans males show signs of body dissatisfaction that are comparable to those exhibited by males being treated for clinical eating disorders and so this group may be more at risk than trans females. Why this difference exists is unclear, but may be related to being birth assigned female and the socialisation effects on body image, or to the differences in the extent to which natal characteristics in each group are regarded. For example, trans males may find the presence of feminine buttocks and hips fundamentally more dissatisfying than trans females find their lack of them to be. Thus, there may be a gender difference with regards to how the different groups perceive their characteristics; as something to be removed as opposed to something to be added. However, how this dissatisfaction manifests in 
Running head: Trans individuals and eating disorder risk

behaviour is as yet unknown and future research is needed to explore the eating and exercise behaviours of trans individuals.

\section{Acknowledgements}

The authors would like to thank Amanda Davey and Dr Emma Haycraft for providing the control data, Dr Meghan Thurnston for setting up the database at the Nottingham Centre for Gender Dysphoria, Joanna Brown for her assistance with inputting data, and Dr Stephan Bandelow for statistical input on an earlier draft of the paper. CIBEROBN is an initiative of ISCIII. 
Running head: Trans individuals and eating disorder risk

\section{References}

Ålgars, M., Alanko, K., Santtila, P., \& Sandnabba, N.K. (2012). Disordered eating and gender identity disorder: A qualitative study. Eating Disorders, 20(4), 300311.

Ålgars, M., Santtila, P., \& Sandnabba, N.K. (2010). Conflicted gender identity, body dissatisfaction, and disordered eating in adult men and women. Sex Roles, 63, 118-125.

American Psychiatric Association (APA) (1994). Diagnostic and Statistical Manual of Mental Disorders, Fourth edition, DSM-IV. Washington, DC: American Psychiatric Association.

American Psychiatric Association (APA) (2013). Diagnostic and Statistical Manual of Mental Disorders, Fifth edition, DSM-5. Washington, DC: American Psychiatric Association.

Appelt, H., \& Strauß, B. (1988).PsychoendokrinologischeGynäkologie [Psychoendrocrinologicalgynaecology]. Stuttgart: Enke.

Arcelus, J., Bouman, W.P., Van De Noortgate, W., Claes, L., Witcomb, G.L., \& Fernandez-Aranda, F. (submitted). Prevalence of Transsexualism: A systematic review and meta-analysis. European Psychiatry Review. 
Running head: Trans individuals and eating disorder risk

Auer, M.K., Hohne, N., Bazarra-Castro, M.A., Pfister, H., Fuss, J., Stalla, G.K., ...\& Isling, M. (2013). Psychopathological profiles in transexuals and the challenge of their special status among the sexes. PLoS ONE, 8(10), e78469.

Becker, I., Cerwenka, S., Nieder, T., Cohen-Kettenis, P., De Cuypere, G., Haraldsen, I., \& Richter-Appelt, H. (2014). Body Satisfaction in Young Gender Dysphoric Adults. World Professional Association for Transgender Health Conference, February 2014.

Boone, L., Soenens, B., \& Luyten, P. (2014). When or why does perfectionism translate into eating disorder pathology? A longitudinal examination of the moderating and mediating role of body dissatisfaction. Journal of Abnormal Psychology, 123(2), 412-418.

Claes, L., Bouman, W., Witcomb, G.L., Thurston, M., Fernandez-Aranda, F., \& Arcelus, J. (2014). Non-suicidal self-injury in transsexualism: Associations with psychological symptoms, victimization, interpersonal functioning and perceived social support. Journal of Sexual Medicine. doi: 10.1111/jsm.12711

Clark, T.C., Lucassen, M.F.G., Bullen, P., Denny, S.J., Fleming, T.M., Robinson, E.M., \& Rossen, F.V. (2014). The health and well-being of transgender high school students: Results from the New Zealand Adolescent Health Survey (Youth '12). Journal of Adolescent Health, 55, 93-99. 
Running head: Trans individuals and eating disorder risk

Clements-Nolle, K., Marx, R., \& Katz, M. (2006). Attempted suicide among transgender persons: the influence of gender-based discrimination and victimization. Journal of Homosexuality, 51(3), 53-69.

Cuzzolaro, M., Vetrone, G., Marano, G.,\& Garfinkel, P.E. (2006). The Body Uneasiness Test (BUT): development and validation of a new body image assessment scale. Eating \& Weight Disorders, 11(1), 1-13.

Davey, A., Bouman, W.P., Arcelus, J., \& Meyer, C. (2014). Social support and psychological wellbeing: A comparison of patients with gender dysphoria and matched controls. Journal of Sexual Medicine. doi: 10.1111/jsm.12681

Degortes, D., Santonastaso, P., Zanetti, T., Tenconi, E., Veronese, A., \& Favaro, A. (2014). Stressful life events and binge eating disorders. European Eating Disorders Review, 22(5), 378-383.

Fernández-Aranda, F., Peri, J.M., Badía-Casanovas, A., Navarro, V., Turón-Gil, V., \& Vallejo- Ruiloba, J. (2000). Transsexualism in Anorexia nervosa: a case report. Eating Disorders: Treatment and Prevention, 8, 63-66.

Fisher, A.D., Castellini, G., Bandini, E., Casale, H., Fanni, E., Ferruccio, N.,...\& Rellini, A.H. (2013). Cross-sex hormonal treatment and body uneasiness in individuals with gender dysphoria. Journal of Sexual Medicine, 11(3), 709719. doi: 10.1111/jsm.12413.

Freund, K., Langevin, R., Satterberg, J., \& Steiner, B. (1977).Extension of the gender identity scale for males. Archives of Sexual Behavior, 6, 515-519. 
Running head: Trans individuals and eating disorder risk

Garner, D. M. (1991). EDI-2.Eating Disorder Inventory-2.Professional manual.

Garner, D.M., Olmstead, M.P., \& Polivy, J. (1983). Development and validation of a multidimensional eating disorder inventory for anorexia nervosa and bulimia. International Journal of Eating Disorders, 2(2), 15-34.

Goodwin H., Haycraft E., \& Meyer C. (2014), Sociocultural Risk Factors for Compulsive Exercise: A Prospective Study of Adolescents. European Eating Disorders Review, 22, 352-359.

Hendricks, M. L., \& Testa, R. J. (2012). A conceptual framework for clinical work with transgender and gender nonconforming clients: An adaption of the Minority Stress Model. Professional Psychology: Research and Practice, (43)5, 460467. doi: 10.1037/a0029597

Hepp, U., Milos, G., \& Braun-Scharm, H. (2004). Gender identity disorder and anorexia nervosa in male monozygotic twins. International Journal of Eating Disorders Review, 35(2), 239-243.

Hepp, U., Spindler, A., \& Milos, G. (2005). Eating disorder symptomatology and gender role orientation. International Journal of Eating Disorders, 37(3), 227233. 
Running head: Trans individuals and eating disorder risk

Hoek, H.W. (1993). Review of the epidemiological studies of eating disorders. International Review of Psychiatry, 5(1), 61-74.

Hudson, J.I., Hiripi, E., Pope, H.G., \& Kessler, R.C. (2007).The prevalence and correlates of eating disorders in the National Comorbidity Survey Replication. Biological Psychiatry, 62, 348-358.

Kroon Van Diest, A.M., \& Perez, M. (2013). Exploring the integration of thin-ideal internalization and self-objectification in the prevention of eating disorders. Body Image, 10(1), 16-25.

Liu, R.T., \& Mustanski, B. (2012). Suicidal ideation and self-harm in lesbian, gay, bisexual, and transgender youth. American Journal of Preventative Medicine, 42(3), 221-228.

McNeil, J., Bailey, L., Ellis, S., Morton, J., \& Regan, M. (2012). Trans Mental Health and Emotional Wellbeing Study 2012. Retrieved online on $23^{\text {rd }}$ June 2014: http://www.scottishtrans.org/wp-content/uploads/2013/03/trans_mh_study.pdf

Mitchell, K.J., Ybarra, M.L., \& Korchmaros, J.D. (2014). Sexual harassment among adolescents of different sexual orientations and gender identities. Child Abuse \& Neglect, 38, 280-295.

Mosley, P. E. (2009). Bigorexia: bodybuilding and muscle dysmorphia. European Eating Disorders Review, 17, 191-198. 
Running head: Trans individuals and eating disorder risk

Murray, S.B., Boon, E., \& Touyz, S.W. (2013). Diverging eating psychopathology in transgendered eating disorder patients: A report of two cases. Eating Disorders, 21(1), 70-74. doi: 10.1080/10640266.2013.741989.

Nevonen, L., \& Broberg, A.G. (2001). Validating the Eating Disorder Inventory-2 (EDI-2) in Sweden. Eating and Weight Disorders - Studies on Anorexia, Bulimia and Obesity, 6(2), 59-67.

Nieuwoudt, J.E., Zhou, S., Coutts, R.A., \& Booker, R. (2012). Muscle dysmorphia: Current research and potential classification as a disorder. Psychology of Sport and Exercise, 13(5), 569-577.

Núñez-Navarro, A., Agüera-Imbernón, Z.P., Krug, I., Araguz, N., Saldaña S., Jiménez-Murcia, S., Granero, R., Treasure, J., \& Fernández-Aranda, F. (2012). Do men with Eating Disorders differ from women in clinics, psychopathology and personality? European Eating Disorders Review, 20 (1), 23-31.

Palmer, R. L., Christie, M., Cordle, C., Davies, D., \& Kenrick, J. (1987). The clinical eating disorders rating instrument (CEDRI); a preliminary description. International Journal of Eating Disorders, 6, 9-16. 
Running head: Trans individuals and eating disorder risk

Palmer, R., Robertson, D., Cain, M., \& Black, S. (1996). The clinical eating disorders rating instrument (CEDRI); a validation study. European Eating Disorders Review, 4, 149-156.

Pauly, I.B. (1968). The current status of the change of sex operation. Journal of Nervous \& Mental Disease, 147(5), 460-471.

Richards, C., \& Barker. M. (2013). Sexuality and gender for mental health professionals: A practical guide. London: Sage.

Seal, L.J. (2007). The practical management of hormonal treatment in adults with gender dysphoria. In Barrett, J. (Ed).Transsexual and Other Disorders of Gender Identity; a practical guide to management. Radcliffe Publishing Ltd, UK.

Stice, E., \& Shaw, H.E. (2002). Role of body dissatisfaction in the onset and maintenance of eating pathology: A synthesis of research findings. Journal of Psychosomatic Research, 53(5), 985-993.

Tsoi, W.F. (1988). The prevalence of transsexualism in Singapore. Acta Psychiatrica Scandinavica, 78(4), 501-504. 
Running head: Trans individuals and eating disorder risk

van Strien, T., \& Ouwens, M. (2003).Validation of the Dutch EDI-2 in one clinical and two nonclinical populations. European Journal of Psychological Assessment, 19(1), 66-84.

Vocks, S., Stahn, C., Loenser, K., \& Legenbauer, T. (2009). Eating and body image disturbances in male-to-female and female-to-male transsexuals. Archives of Sexual Behavior, 38(3), 364-377.

Van Caenegem, E., Taes, Y., Wierckx, K., Vandewalle, S., Toye, K., Kaufman, J.,...\& T'Sjoen, G. (2013). Low bone mass is prevalent in male-to-female transsexual persons before the start of cross-sex hormonal therapy and gonadectomy. BONE, 54(1), 92-97.

Wålinder, J. (1971). Incidence and sex ratio of transsexualism in Sweden. The British Journal of Psychiatry, 119, 195-196. doi:10.1192/bjp.119.549.195

Waller, G., Ormonde, L., \& Kuteyi, Y. (2013), Clusters of personality disorder cognitions in the eating disorders. European Eating Disorders Review, 21, 28-31.

Whittle, S., Turner, L., \& Al-Alami, M. (2007). Engendered penalties: Transgender and transexual people's experiences of inequalities and discrimination. The 
Running head: Trans individuals and eating disorder risk

Equalities Review. Retrieved on $23^{\text {rd }}$ June 2014 from http://www.pfc.org.uk/pdf/EngenderedPenalties.pdf

Winston, A.P., Acharya, S., Chaudhuri, S., \& Fellowes, L. (2004). Anorexia nervosa and gender identity disorder in biologic males: a report of two cases. International Journal of Eating Disorders, 36(1),109-113.

Witcomb, G.L., Arcelus, J., \& Chen, J. (2013). Can cognitive dissonance methods developed in the West for combatting the 'thin ideal' help slow the rapidly increasing prevalence of eating disorders in non-Western cultures? Shanghai Archives of Psychiatry, 25(6), 332-341.

World Health Organization (1992). International classification of disease 10 (ICD-10). Geneva: World Health Organization. 
Running head: Trans individuals and eating disorder risk

Table 1. Mean (SD) age and EDI-2 scores for the three groups matched on desired gender.

\begin{tabular}{|c|c|c|c|c|c|c|c|c|c|}
\hline & \multicolumn{3}{|c|}{ Trans group } & \multicolumn{3}{|c|}{ Eating disorder group } & \multicolumn{3}{|c|}{ Control group } \\
\hline & $\begin{array}{c}\text { Trans male } \\
\mathrm{n}=75\end{array}$ & $\begin{array}{c}\text { Trans female } \\
n=125\end{array}$ & $\begin{array}{c}\text { All } \\
N=200\end{array}$ & $\begin{array}{c}\text { Cisgender } \\
\text { Male } \\
n=75\end{array}$ & $\begin{array}{c}\text { Cisgender } \\
\text { Female } \\
n=125\end{array}$ & $\begin{array}{c}\text { All } \\
N=200\end{array}$ & $\begin{array}{c}\text { Cisgender } \\
\text { Male } \\
n=75\end{array}$ & $\begin{array}{c}\text { Cisgender } \\
\text { Female } \\
n=125\end{array}$ & $\begin{array}{c}\text { All } \\
N=200\end{array}$ \\
\hline Age & $25.36(9.60)$ & $38.56(14.21)$ & $33.61(14.19)$ & $30.80(11.83)$ & $29.50(10.57)$ & $29.99(11.05)$ & $33.69(8.81)$ & $46.70(122.35)$ & $41.82(96.94)$ \\
\hline Drive for thinness & $4.13(5.38)$ & $4.04(4.97)$ & $4.08(5.11)^{\star}$ & $11.61(6.20)$ & $14.50(5.63)$ & $13.42(6.00)^{\star / \star \star}$ & 1.08 (1.89) & $4.10(4.97)$ & $2.97(4.34)^{\star \star}$ \\
\hline Bulimia & $1.76(3.20)$ & $1.47(3.21)$ & $1.58(3.20)^{\star}$ & $7.31(6.21)$ & $7.31(6.19)$ & $7.31(6.18)^{\star / \star \star}$ & $0.68(1.28)$ & $1.74(2.90)$ & $1.35(2.47)^{\star \star}$ \\
\hline Body dissatisfaction & $14.73(8.30)$ & $9.91(6.24)$ & $10.72(7.44)^{\star / \star \star \star ~}$ & $13.95(7.51)$ & $19.30(7.90)^{\star / \star \star}$ & $17.30(8.16)$ & $4.31(4.55)$ & $8.89(7.22)$ & $7.17(6.72)^{\star \star / \star \star \star}$ \\
\hline
\end{tabular}

* Tukey's post-hoc test difference between Eating Disorder and Trans: $p<0.05$

** Tukey's post-hoc test difference between Eating Disorder and Controls: $p<0.05$

***Tukey's post-hoc test difference between Trans and Controls: $p<0.05$ 
Figure 1: Mean (SD) EDI-2 scores for the three groups, matched on desired gender.
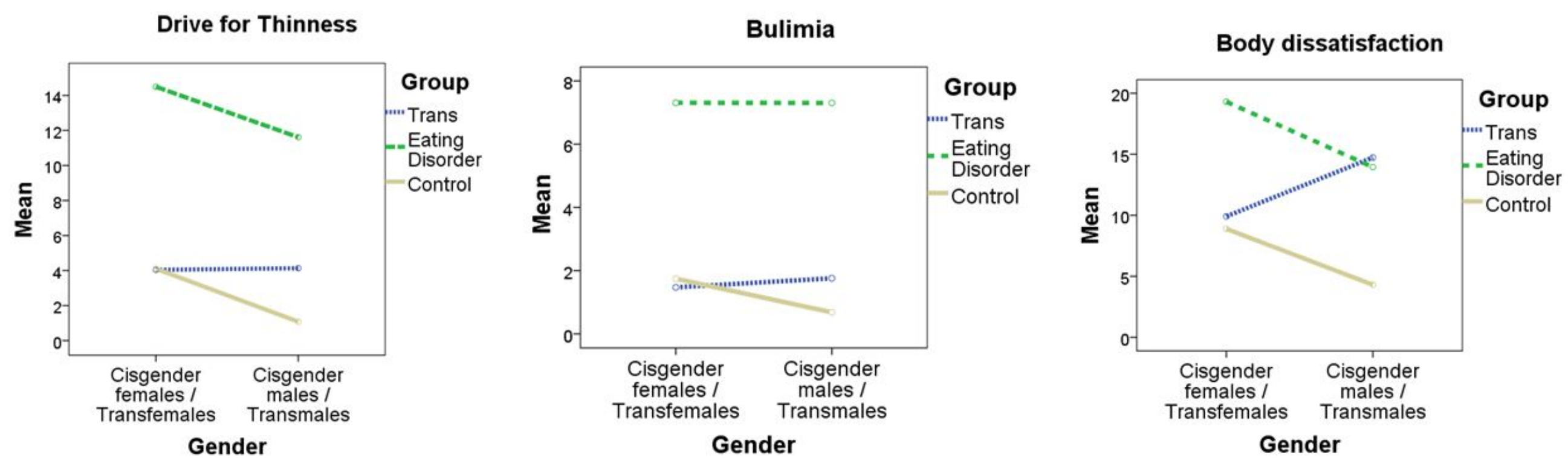